\title{
Ubiquitin Carboxyl-Terminal Hydrolase 46
}

National Cancer Institute

\section{Source}

National Cancer Institute. Ubiquitin Carboxyl-Terminal Hydrolase 46. NCI Thesaurus.

Code C158826.

Ubiquitin carboxyl-terminal hydrolase 46 (366 aa, $~ 42 \mathrm{kDa}$ ) is encoded by the human USP46 gene. This protein plays a role in the regulation of glutamate-dependent responses and protein deubiquitination. 